\title{
Estar Turista (turi-estar), Discursos Espaciais e Sentidos de Eficiência Multiterritorial: uma breve análise do Plano Aquarela (2003-2006) / Embratur
}

RESUMO: Esse ensaio busca discutir como os sentidos de se fazer turismo (turi-estar) perpassam por dimensões multiterritoriais. Enquanto exercício de nossa indagação faremos uma breve apreciação do Plano Aquarela (2003-2006), plano esse de metas, dados, entre outras questões, atinentes a divulgação turística do Brasil no exterior, vinculado ao Instituto Brasileiro de Turismo (Embratur). Antes debateremos algumas questões referentes a formação dos sentidos no âmbito de turi-estar. Posteriormente, nosso argumento perpassa por uma efetivação dos discursos dos sentidos plurais por meio de uma cultura capitalista. Na análise efetiva das ações da Embratur no âmbito do Plano Aquarela, destacamos como suas ações contém estratégias espaciais concatenando apropriações representativas e possivveis usos efetivos de espacialidades (multi-localizadas) na efetivação dos sentidos daqueles (estrangeiros) que buscam se estabelecer em temporalidades específicas no espaço brasileiro, valendo-se de suas potencialidades em multiterritorializar-se.

\section{Tourist being (turi-being), Discourses and Meanings of Spatial efficiency multi-territory: a brief analysis of the Aquarela Plan (2003-2006) / Embratur}

\section{Almir Nabozny*}

Cleder Fontana**

*Doutorando no Programa de PósGraduação em Geografia, Universidade Federal do Rio Grande do Sul.

**Doutorando no Programa de PósGraduação em Geografia, Universidade Federal do Rio Grande do Sul.
Palavras-chave: Sentidos; Multiterritorialidade; Turismo.

Key-words: Senses; Multi-territory; Tourism.

\begin{abstract}
This essay discusses how the senses of sightseeing (turi-being) permeate by multi-territory size. While the exercise of our inquiry will make a brief assessment of the Aquarela Plan (2003-2006), this plan of goals, data, among other issues, pertaining to disclosure Brazil's tourism abroad, linked to the Brazilian Tourism Institute (Embratur). Before we will discuss some issues concerning the formation of sense in the context of turi-being. Subsequently, our argument goes through for a realization of the speeches of plural senses through a capitalist culture. In the actual analysis of the actions of Embratur under the Aquarela Plan, we highlight how their actions contains appropriations representative concatenating spatial strategies and possible effective uses of spatiality (multi-located) in the effectuation of the senses of those (foreigners) who seek to establish specific time frames in Brazilian space, taking advantage of its potential to be multi-territorialized.
\end{abstract}


1 Expressões atinentes ao território como "atributo" e "propensão para" são anotações de aulas dos autores. Cunhadas pelo professor Álvaro Luiz Heidrich na disciplina "Espaço Social e Condição Territorial" ofertada pelo Programa de Pós-Graduação em Geografia da Universidade Federal do Rio Grande do Sul (UFRGS). Da qual as reflexões desse texto são oriundas. Também aproveitamos para agradecer ao professor pelas sugestões e críticas no decorrer da disciplina.
Geografia Ensino \& Pesquisa, v. 15, n.2, p. 105 116, maio./ago. 2011

Estar Turista (turi-estar), Discursos Espaciais e Sentidos de Eficiência Multiterritorial: uma breve análise do Plano Aquarela (2003-2006) / Embratur

\section{Introdução}

Para elucubrarmos esse texto partirmos da perspectiva de compreender como os sentidos do turi-estar pressupõem da multiterritorialidade (?). Decompúnhamos nossa interrogação entorno de dois conceitos cuja discussão faremos de forma imbricada, sentidos e multiterritorialidade e, um neologismo (uma espécie de verbo) que elaboramos enquanto um meta-conceito, turi-estar. Demarquemos desse modo que estamos discutindo a pluralidade de sentidos na Modernidade, conforme apreciadas por Berger e Luckmann (2005), o que não significa um total acolhimento do argumento mas, um ponto de partida. Em que acrescentamos os dimensionamentos espaciais, enquanto localização multi-relacional (GOMES, 2006).

Ante debater o fenômeno turístico, discutiremos efetivamente o sentido duplo e complementar em se fazer turismo (turi-estar). Argumentando que não existe o que se denomina de turista (enquanto configuração de uma identidade), mas sim pessoas que estão praticando uma atividade turística, concatenando em um estar turístico, numa temporalidade e espacialidade específica, enquanto uma ocupação de uso determinada (territorialidade), perpassando por aquele que esta a turi-estar sentidos que angariam as práticas. No entanto, 0 processo de conjunção desse desejo de viajar pode ser confabulado em diferentes espacialidades e, posteriormente comunicado, mas a eficiência desse discurso se conjuga na recepção criativa, no espaço social do grupo de convivência. Eficiência configurada pela reciprocidade entre aquilo que é ofertado e o desejo despertado pelo receptor da mensagem, a qual é permeada por duas dimensões espaciais, duas localizações de relações, a do estar (receptor) e do querer (onde ir). Contudo, é um sentido potencial cuja efetivação demanda de uma nova espacialidade; ou seja, o deslocamento e o uso efetivo de uma determinado "produto (espacial) turístico".

Nesse influxo de sentidos do viajar que recorremos ao conceito de multiterritoralidade, angariando potencialidade espacial para se deslocar e, as práticas de incursão em novas espacialidades, criando propensões territoriais ${ }^{1}$, ou melhor, dizendo multiterritorialidades, tal qual configurada por Haesbaert $(2007,2008)$. Compondo no sentido da ação de fazer turismo uma sobreposição de planos de representação espacial em múltiplas localizações espaciais (GOMES, 2006) apregoadas pelo estabelecimento de territorialidades (SACK, 1986), ou seja, relações, práticas e ações de controle espacial necessárias à vida social.

E quais seriam os sentidos do turi-estar? Antes de discutirmos essa interrogação se faz necessários evidenciarmos as imbricações produtoras de sentidos. Assim, recorremos a Berger e Luckmann (2005), os quais ressaltam que os sentidos especificamente se realizam no jogo da consciência individual e, no processo de sociabilidade, sendo que a consciência (não é vazia) é sempre consciência de algo, representações e intenções para um núcleo (de significância) permeada pela vivência do sujeito, o qual é constituído de forma relacional pela experiência. Dessa forma interações formam os sentidos. No singular,

nada mais é do que uma forma complexa de consciência: não existe em si, mas sempre possui um objeto de referência. Sentido é a consciência de que existe uma relação entre as experiências (BERGER e LUCKMANN, 2005. p.15).

Em que os sentidos permearam as ações, por mecanismos de ponderações de valores, em que 0 agir se caracteriza num "sistema retroativo". Por um lado, é projetivo (projeto, utopia, planos, passos) por outro lado, é reflexivo, ou seja, caracterizando-se por uma significância 
prévia, se devo, e porque agir. Contudo, ressaltemos que o indivíduo (ser social) e seus processos de sociabilidade se configuram em dimensões espaciais.

Os múltiplos dimensionamentos espaciais serão explorados no texto por meio de uma breve análise do Plano Aquarela (2003-2006) que se constitui em estratégias de marketing turístico internacional do Brasil. $\mathrm{O}$ qual foi pensando como um instrumento técnico reflexivo $\mathrm{e}$ projetivo das ações brasileiras no incentivo ao turismo internacional a ser realizado no Brasil, do qual iremos discutir quais são os discursos espaciais vinculados ao plano no que tange ao "espaço de venda" do produto turístico e, quais serão os desejos angariados pelos turistas que vem ao Brasil, uma vez que o Plano Aquarela traça cenários referentes aos visitantes e potenciais clientes do turismo brasileiro.

Ressaltamos que realizamos uma leitura sistemática do Plano Aquarela por meio e agrupamentos semânticos, de modo, a aglutinarmos grupos de informações que pudessem ser categorizados enquanto intenções (do plano) e que configurassem ao mesmo tempo visões sociais dos agentes da Embratur com relação ao Turismo internacional no Brasil. Uma vez feita a leitura do texto final do Plano Aquarela e leituras referente as informações contidas no sítio eletrônico da Embratur é que nos apercebemos de uma gênese discursiva em relação ao turismo internacional vinculados a estratégias de apelo espacial, sugerindo intencionalidades e perspectivas de apropriações no discurso e potencialmente a efetivações posteriores por meio da vinda das pessoas para praticarem o turismo nas espacialidades brasileiras.

\section{Os sentidos e as territorialidades à montante do turi-estar}

Talvez o fator mais importante no surgimento de crises de sentido na sociedade e na vida do indivíduo não seja o pretenso secularismo moderno, mas o moderno pluralismo. Modernidade significa um aumento quantitativo de pluralização (...). O pluralismo moderno leva a um enorme relativismo dos sistemas de valores e da interpretação (BERGER e LUCKMANN, 2005. p.49-50).

As últimas décadas do século XX foram marcadas pelo debate entre fim ou permanência de estruturas econômicas-políticas-sociais, implicando, especificamente na ciência geográfica, na compreensão e explicitação das questões espaciais. Expressões como "fim da história", "adeus ao proletariado", "modernidade líquida", "não-lugares", "desterritorialização", entre outras, que de modo geral estão associadas a discussão das "contrações" tempo e espaço, apontam para as tendências "flexíveis" da atualidade como contraposição a "rigidez" dos tempos passados.

Contudo, diversas adjetivações que são feitas as expressões por nós expostas se configuram no bojo da própria Modernidade, se recortarmos para o campo que estamos discutindo, os sentidos, como configurados por Berger e Luckmann (2005). Porém, nos perguntamos se efetivamente não haveriam mais instituições (ou ainda estruturas) capazes de gestarem e comunicarem ordens supra-ordenadas de sentidos?

Em Condição pós-moderna, Harvey (1998), que se propõe a fazer uma crítica a noção pósmoderna, procura demonstrar que as diferenças nas manifestações culturais, nos processos de produção e organização do trabalho, insurgentes sobretudo a partir dos anos 1970, não alteram Geografia Ensino \& Pesquisa, v. 15, n.2, p. 105-116, maio./ago. 2011 as regras da acumulação, expressada pela incessante busca pelo lucro. No entanto, em relação 
${ }^{2} \mathrm{O}$ que nos força a uma leitura para além da visão setorial no mundo contemporâneo. Nosso argumento é que ocorrem múltiplos planos de investimentos pelos agentes capitalísticos, concatenando efetivamente múltiplas seleções e apropriações espaciais. Isso pode ser vislumbrado, por exemplo, na agricultura quando Oliveira (2005) evidencia estratégias ora de monopolização territorial, ora de territorialização do capital no campo.

3 Nas referências consta-se Guatarri e Rolnik (1986), no entanto as ideias são do primeiro autor.

Geografia Ensino \& Pesquisa, v. 15, n.2, p. 105 116, maio./ago. 2011

Estar Turista (turi-estar), Discursos Espaciais e Sentidos de Eficiência Multiterritorial: uma breve análise do Plano Aquarela (2003-2006) I Embratur as possíveis transformações da economia política do capitalismo do final do século XX, afirma que "são abundantes os sinais e marcas de modificações radicais em processo de trabalho, hábitos de consumo, configurações geográficas e geopolíticas" (HARVEY, 1998, p. 117).

Em contraposição a rigidez do fordismo, Harvey (1998) aponta a "acumulação flexível" que, assentada na emergência de novos setores de produção e novos mercados, baseados em inovações comerciais, tecnológicas e organizacionais, implicam na flexibilidade dos processos de trabalho, dos mercados de trabalho, nos produtos e padrões de consumo, de maneira que permita uma intensificação da reprodução do próprio sistema como um todo. Este processo, que envolve rápidas mudanças nos chamados setores econômicos como, entre as regiões geográficas, levou a um amplo movimento no setor de serviços.

O capital tornou mais flexíveis os setores produtivos ${ }^{2}$, os processos, os produtos, mas também tornou mais passageiras as modas, os estilos de vida, abrindo alas para filões de mercado ligados as sensações e as emoções. A necessidade de acelerar o tempo de giro do capital implica na aceleração do consumo, possibilitando, nos novos nichos, vide a produção de bens como saúde, educação, mas sobretudo, para nossos interesses por ora em debate, a questão dos espetáculos, dos eventos, da diversão e do laser, atrelados, em grande parte, com o fenômeno do turismo.

Harvey (1998, p. 307) entende o capitalismo como um "processo de reprodução da vida social por meio da produção de mercadorias" que envolve todas as pessoas do mundo capitalista. Enquanto processo, o capitalismo transforma incessantemente a sociedade em que está inserido. É um processo de "destruição criativa" que "cria novos desejos e necessidades, explora a capacidade do trabalho e do desejo humano, transforma espaços e acelera o ritmo da vida" (HARVEY, 1998, p. 307). Por isso, para o autor a vida cultural não pode ser considerada como exterior a essa lógica, como argumento ele pontua: i - não haver diferença entre a "gama de atividades especulativas" realizadas por empreendedores e o "desenvolvimento igualmente especulativo de valores e instituições culturais, políticos, legais e ideológicos sob o capitalismo", ou seja, tanto a produção de objetos, quanto à produção de discursos religiosos, por exemplo, são objetivados em condições especulativas; ii - mesmo que seja possível uma elaboração de valores, ideias e crenças independentes e, antecedentes a hegemonia do capitalismo, a muito elas estão sendo produzidas de maneira imbricada não sendo

reforçados nem descartados de acordo com as racionalizações post hoc da obtenção de lucros, a lucratividade há muito está implicada nessas atividades e, com a passagem do tempo, a força dessa ligação antes aumentou do que diminuiu (HARVEY, 1998, p. 308).

Estamos salientando algumas configurações em torno de uma discussão cultural, por vislumbramos que em muitos casos as ideias de turi-estar vem acopladas as concepções de bens culturais, valorização cultural, bem como ao chavão "indústria limpa", associados ao ócio, emoções e sensações. Todavia, o que estamos evidenciando enquanto cultura até então esta atrelada ao modo discursivo em que a cultura tem sido apropriada. Embora, Harvey (1998) enseja seu debate na matriz da teoria social crítica, sua discussão cultural pode ser triangulada com acepções metodológicas diferenciadas, como fazemos nesse caso associando 0 argumento de Guatarri (1986)3 , o qual evidencia que corriqueiramente a cultura é conceituada e acatada enquanto uma sujeição à subjetividade, configurando uma ideia reacionária para 0 autor, equivalente a discussão de sujeição do capital ao econômico.

Entretanto, Guatarri (1986) destaca que há um processo de singularização que nos leva a 
um modo total de viver. Segundo o autor a palavra cultura aparecia como um impedimento para pensar a realidade desses processos. Prossegue destacando três núcleos semânticos qualificativos da "cultura" na literatura em voga. Primeiro a cultura como um valor, um segundo núcleo seria a cultura enquanto sinônimo de civilização e, uma terceira semantização, a mercadoria. Em que muito do que se denomina de cultura não é uma concepção ou, uma ideia conceitual, mas algo que se encaixa em modelos. A crítica se estende no âmbito dos debates da "transmissão" da cultura, que para o autor não pode ser pensado como se existisse uma homogeneidade social. Disso destacam-se as diferenças confabuladas justamente por meio das espacialidades sociais.

O aspecto fundamental debatido é uma cultura capitalista, a qual promove um mercado de poder, em que

Não existe, a meu ver, cultura popular e cultura erudita. Há uma cultura capitalística que permeia todos os campos de expressão semiótica.(...). Assim como o capital é um modo de semiotização que permite um equivalente geral para as produções econômicas e sociais, a cultura é o equivalente geral para as promoções do poder (GUATARRI, 1986. p.23-24).

Um elemento fortemente debatido é a subjetividade enquanto uma matéria-prima para todos os sistemas produtivos. Contrapondo as teorias que tentaram explicações pelo viés ideológico, considerando que muitos conflitos não se vinculam a uma somatória de subjetividades na escala mundo.

Outro aspecto importante frisado por Guatarri (1986) é a polarização indivíduo versus sociedade. Dicotomia da qual o autor se opõe, ao considerar que há um agenciamento coletivo de emancipação, uma espécie de diálogo entre as duas forças, onde se produz a subjetividade, "ou seja, toda a produção de sentido, de eficiência semiótica" (GUATARRI, 1986. p.31 - grifos nossos).

Nisso, retornamos Berger e Luckmann (2005) quando falam de pluralismo moderno enquanto a matriz de sentidos. Em que concordamos que não se pode argumentar que haja uma instituição supra ordenada de sentidos. Pois, o modo total de produção capitalista (HARVEY, 1998; LEFEBVRE, 2001) ou a cultura capitalística (GUATARRI, 1986) não configuram-se como agentes (instituições).

Todavia, salientamos que podem haver agentes instituintes desses modos de agenciamentos coletivos que intencionalmente desejam que a totalidade se configure ou, se apresente enquanto uma pluralização identitária para citarmos um processo analisado por Hall (1998). Entre outros processos vinculados aquilo que o autor denomina identidades de resistências, tais como lutas étnicas, lutas sexuais, entre outros possibilidades pluri-identitárias, em que acrescentamos o estar fazendo turismo como mais uma relação de identificação e angariamento de um devir, porém, essa última é transitiva espaço-temporal, configurando uma expansão de comunidades de vida para valermos dos termos de Berger e Luckmann (2005). Assim, há um aumento da eficiência capitalística por meio da exploração de nichos de comunidades concatenados por identidades específicas. E que se tornam mais eficientes na sociedade contemporânea justamente por projeções de poderes no espaço instituindo relações de territorialidade com propensões para o controle dos fluxos, dos dutos e as conexões, tendendo as vezes para efetiva formação de um território rede para citarmos os termos de Haesbaert (2004).

Geografia Ensino \& Pesquisa, v. 15, n.2, p. 105-116, maio./ago. 2011

Nabozny, A.; Fontana, C. 
4 Fato exemplificado quando das declarações do "ator" Sylvester Stallone na impressa mundial sobre a gravação do filme "Os mercenáros" (filmados no Brasil em 2009): "Você pode explodir o país inteiro e eles vão dizer 'obrigado, e aqui está um macaco para você levar de volta para casa"'.
Geografia Ensino \& Pesquisa, v. 15, n.2, p. 105 116, maio./ago. 2011

Estar Turista (turi-estar), Discursos Espaciais e Sentidos de Eficiência Multiterritorial: uma breve análise do Plano Aquarela (2003-2006) / Embratur

\section{Estratégias espaciais da Embratur: discursos e ações multiterritorializados e sentidos espaciais a jusantes do turi-estar}

Nossa intenção nesse trecho vincula-se ao desdobramento de nossa questão central de argumento a uma breve apreciação do "Plano Aquarela" (2003-2006) encabeçado pelo Instituto Brasileiro de Turismo (EMBRATUR). Destaca-se que essa empresa governamental, atualmente vinculada ao Ministério do Turismo. Inicialmente foi criada em 1966 no range do Regime Militar vinculada à necessidade de estabilizar a economia brasileira, sendo o turismo entendido nesse momento como uma atividade geradora de empregos, renda e recursos em divisas. Alfonso (2006) elenca como principais aspectos vinculados a esse período a entrada de moedas estrangeiras, integração econômica e social, desenvolvimento regional e integração política e econômica. Sendo que atualmente a Embratur tem por missão principal a divulgação turística do Brasil no exterior.

Assim, queremos salientar quais são os principais atributos geográficos atrelados aos discursos de marketing angariados pela Embratur no que tange do "Plano Aquarela". Ressaltemos que buscaremos triangular nossas leituras em permeação com Alfonso (2006) a qual fez uma qualificação entorno das imagens "vendidas" do Brasil no exterior no período de 1970 a 2002 por meio das estratégias de divulgação turísticas conduzidas pela Embratur, ressaltando que a produção e a compreensão dessas imagens relacionam-se intimamente com as formas espaciais.

Como busquemos arregimentar em nossos argumentos somos partidários de Berger e Luckmann (2005) quanto à pluralidade de sentidos. Contudo, também ressaltemos em Guatarri (1986) e Harvey (1998) que essa pluralidade pode perpassar por interesses de agentes que se hegemonizam por meio de um sistema de produção total de vida. E que, portanto, a fragmentação do social confabulada por uma pluralidade de sentidos perpassa por sustentações de discursos que se apresentam como que isentos de uma intencionalidade.

Dessa forma nossa argumento é que a Embratur na análise do turi-estar perpassa por um "órgão/empresa" sui generis uma vez que concatena múltiplos interesses representativos de outras empresas vinculadas ao ramo do turismo, redes hoteleiras, companhias aéreas, entre outras. Ao mesmo tempo em que alimenta fora do território nacional representações hegemonizadas em relação ao Brasil. Dessa forma respaldando ou contrapondo a confabulação de viajar do estrangeiro.

Mas ao lermos o trabalho de Alfonso (2006) percebemos que a Embratur vendeu uma imagem exótica do Brasil vinculado aos seguintes eixos norteadores: mulher bonita, exacerbação da sexualidade e grandes festividades nacionais como o carnaval, por exemplo, principalmente vinculado as espacialidades litorâneas do Brasil e, com um forte apelo à cidade do Rio de Janeiro. Configurando inclusive que muitas representações que atualmente são vinculadas por estrangeiros nas mídias em geral perpassam por um núcleo representativo que tiveram por longo período o próprio Estado brasileiro (por meio da Embratur) como um agente produtor dessa estereotipagem ${ }^{4}$, daquilo que configurara uma imagem/representação espacial de Brasil.

Inclusive como verificado por Alfonso (2006) existe atualmente um trabalho efetivado na esfera da recepção do estrangeiro no Brasil no sentido de combater a exploração sexual comercial de meninos e meninas, como se nas entrelinhas houvesse um reconhecimento da ocorrência desse fenômeno social vinculado aos estrangeiros e, que por ora isso não seria mais permitido. No entanto a configuração dos sentidos, do desejo em outra espacialidade vinculado à 
experiência do estrangeiro em muitos casos podem serem frutos justamente desse acolhimento erotizado das espacialidades brasileira vinculada pela própria Embratur durante um longo período.

Isso remete-nos que a ideias e as representações sexualizadas de Brasil tiverem (e tem) uma receptividade nas esferas dos sentidos dos sujeitos viajantes para o Brasil. E que atualmente perpassaria por necessidade de reconstrução da mesma. Interessando-nos em perguntar: Quais seriam as atuais tentativas de vendas (formas) espaciais efetivadas por meio do "Projeto Aquarela?" Quais os sentidos são vinculados (atraídos)? E quais são as realizações multiterritoriais?

Ao mesmo tempo em que partindo do ponto de vista do turismo, o processo de reprodução do espaço pode levar a uma mercadorização deste, também se pode pensar na interação de agentes enquanto disputas por afirmações. Como agentes, neste caso, pensamos, sobretudo, nos turistas ("usuários"), no Estado (agente regulador e incentivador), nas empresas de turismo (promotoras) e na mídia (divulgadora). Considerando as afirmações, pensamos no uso, como um primeiro atributo para discutir a questão do território, neste caso, mais especificamente, uma territorialidade, entendida como uma propensão para (possibilidade de) configurar territórios.

Afirmamos isso no sentido de um esforço de pensar as realidades (materiais e ideais ${ }^{5}$ ) destinadas ao turismo como referenciais de vivências construídas pelo Estado, empresas de turismo, mídia e pelos próprios turistas, como territorialidades que pressupõem uma alimentação, por parte dos turistas, em outras territorialidades, mais precisamente, naquelas vivências mais cotidianas, como do trabalho e a habitação.

Em 2003, com a criação do Ministério do Turismo, a Embratur direcionou-se para 0 mercado do turismo internacional. Para o Ministério do Turismo, a Embratur é uma autarquia especial

responsável pela execução da Política Nacional de Turismo no que diz respeito à promoção, marketing e apoio à comercialização dos destinos, serviços e produtos turísticos brasileiros no mercado internacional (BRASIL, 2010.s/p).

Desde 2003 a Embratur tem o Plano Aquarela - Marketing Turístico Internacional do Brasil como orientador de suas ações. Este plano trata-se de um relatório executivo de uma empresa de marketing, a Chias marketing. Assim, o que se encontra no site da Embratur está diretamente atrelado ao Plano Aquarela, ou seja, consiste em um plano de marketing que, quando de sua elaboração, teve três fases: i) diagnóstico; ii) formulação de estratégias de marketing e iii) plano operacional.

Quanto a origem e procedência do turista internacional no Brasil, o Plano Aquarela aponta uma tendência nos últimos anos de crescimento de participação da Europa e da América do Norte. De 1900 para 2000, no total de turistas internacionais recebidos pelo Brasil, a Europa passou de 30 para 39\% e a América do Norte de 13 para 19\%. Por sua vez, a participação dos países da América do Sul caiu de 49 para 37\%. O estado de São Paulo é a grande porta de entrada, mesmo quando o turista tem outro destino interno. Por sua vez, esta entrada ocorre de maneira relativamente concentra entre os meses de dezembro a março (BRASIL - PLANO AQUARELA, p. 18. s/d).

Em termos de discursos potenciais para o turismo oferecido pelo Brasil, o Plano Aquarela remete-se as espacialidades brasileiras enfatizando a diversidade ambiental, étnico-cultural, climas e paisagens como recursos que podem combinar interesses e atividades múltiplas
${ }^{5}$ Aqui pensamos na "La double réalité (matérielle e idéelle) de l'espace social" de Di Méo e Buléon (2007).
Geografia Ensino \& Pesquisa, v. 15, n.2, p. 105-116, maio./ago. 2011

Nabozny, A.; Fontana, C. 
enquanto características específicas do Brasil, resultando na formação de cinco grande segmentos e diversos nichos de mercados enfocados a partir de cada um dos segmentos. Os cinco segmentos são: sol \& praia, ecoturismo, cultura, esporte e negócios \& eventos. Os produtos oferecidos pelo turismo, segundo o Plano Aquarela, podem serem vistos, em forma de ranking, com valor potencial (valor intrínseco, singularidade e caráter brasileiro) e com valor real (notoriedade e concentração da oferta). A Embratur, de acordo com o seu site, divulga em possiveis destinos para os turistas, recortes espaciais de Brasil a partir dos segmentos apontados pelo Plano Aquarela.

Além disso, o Plano Aquarela, enquanto estratégia de marketing, para a divulgação turística internacional, defende a criação de uma mensagem global para todos os mercados, a qual se daria através de três elementos: i) conjunto de argumentos e de valores que levam o turista potencial a conhecer o Brasil; ii) slogan que sintetize todos os argumentos e valores e iii) marca turística como elemento de identidade. Todos estes elementos encontram-se no site e também tem como objetivo a distribuição em materiais promocionais, como divulgação do turismo no Brasil. A "marca turística", sobreposição de cores verde, amarelo, azul, vermelho e branco, com partes que extrapolam umas as outras, com o nome do país no centro e a expressão "sensacional!" logo abaixo, tem posição de destaque no site e, segundo o Plano Aquarela , destaca-se entre o conjunto de marcas mais importantes do mundo. Além disso, o Plano Aquarela apresenta dados de médias de despesas diárias, tempo de permanência e sobre possíveis intenções em conhecer o Brasil, definindo assim, mercados turísticos alvos, afirmando que em Portugal e na França o Brasil está posicionado como primeiro destino de interesse de viagem.

Assim, a partir do exposto pelo Plano Aquarela e que, enquanto concretização encontra-se no site da Embratur e, também, pelas formas de divulgação do turismo no Brasil antecedentes ao período em que a Embratur direciona-se para o turismo internacional, entendemos ser possível pensar no sentido de que a ação de fazer turismo é o resultado do imbricamento de dois sentidos, o de atrair e do ir (vir) a algum destino. E, no que diz respeito as suas implicações geográficas, este processo pode se dar em tempos e espaços diferentes, de acordo com a eficiência da comunicação das intenções, mais precisamente dos sentidos (BERGER e LUCKMANN, 2005), por sua vez, a ocorrência destes repercute em territorialidades tal qual concebidas por Haesbaert (2008), ao mesmo tempo que fazem parte de um processo capitalista, podendo serem consideradas a partir das diferentes leituras, como de Harvey (1998) e Guatarri (1986).

Os agentes turísticos (nesse caso a Embratur) por meio de suas ações promovem recortes imagéticos do espaço geográfico (seleção morfológica, representações parciais), fundantes de suas publicidades, uma espécie de venda da paisagem geográfica. No entanto, a dupla efetivação do turismo (atração e estar) produzida pelo agente turístico promove uma ocupação e, um uso no estar do sujeito que se efetiva enquanto deslocante espacial e são nessas imbricações de ocupações e usos que se produzem territorialidades.

As territorialidades engendram relações de poder, no entanto não necessariamente

Geografia Ensino \& Pesquisa, v. 15, n.2, p. 105116, maio./ago. 2011

Estar Turista (turi-estar), Discursos Espaciais e Sentidos de Eficiência Multiterritorial: uma breve análise do Plano Aquarela (2003-2006) I Embratur valendo-se de dominação e fechamento, que configuraria um território reclusivo, mas como projeções espaciais de poder buscando uma maior eficiência das ações. Até porque em muitos casos se faz necessário estar aberto (e não recluso) para ocorrência do turismo, a praia, é um exemplo. É pública. Assim, o discurso de empoderamente é paradoxalmente, apropriativo do espaço público, praia, por meio do agente turístico que atraem pessoas para se fazerem turista e, ao mesmo tempo perpassa pela necessidade de estar aberto para visitação facilitando o acesso e a sua mercantilização. Mas os discursos se espraiam e chegam entre outras instância 
no próprio Estado, o qual tem que promover infra-estrutura, entre outras benevolentes, pois afinal no bojo do fenômeno esta o seu discurso de desenvolvimento.

Assim, a própria Embratur na escolha de imagens de Brasil, aciona discursos espaciais para melhor reproduzir os seus efeitos de marketing. Nos termos de Sack (1986) constituísse em estratégias para afetar, influenciar e controlar pessoas, fenômenos e relações. Para isso as pessoas e coisas do espaço brasileiro são circunstanciadas e recortadas em imagens de Brasil que tomam como efeito uma tentativa de totalidade. Assim, visa afetar comportamentos dos estrangeiros no bojo de atração de seus sentidos e desejos ao mesmo tempo que seleciona usos e espacialidades potenciais a visitação. Dessa forma regulando usos do espaço e, impactando diferentemente nas pessoas autóctones dessas determinadas espacialidades.

Configurando nessa territoralidades discursivas e a serem apropriadas elementos daquilo que Carlos (2001) denomina de contradições do espaço. Pois, a produção, não só produz coisas no espaço, mas o próprio espaço enquanto mercadoria. Disso a necessidade de por em pauta o "espaço do consumo-consumo do espaço" (CARLOS, 2001, p. 64). Em que a autora constata que cada vez mais o espaço geográfico são destinados a troca, tendendo a uma maior subordinação ao mercado.

\section{Considerações Finais}

Começamos nossa "viagem" tendo como ancora de discussão a hipótese que os sentidos de turis-estar pressupõe uma dupla imbricação espacial. Primeiro, a localização multi-relacional de confabulação do desejo de viajar. Segundo, as múltiplas possibilidades de viagem e, consequentemente efetivações dos deslocamentos em outras espacialidades. Configuradas na grande ambivalência destacada por Haesbaert (2004), uma pequena elite global que pode escolher por múltiplas territorialidades e uma grande massa de precária territorialização. Onde os sentidos só se efetivam plenamente num plano de sobreposição espacial, ou seja, pelo estabelecimento de relações multiterritoriais. Primeiro, na ordem dos discursos, desejos e potencialidades (financeira, sobretudo) para múltiplas experiências espaciais, ou seja, apropriações representacionais. Segundo, os usos esporádicos e, as ações concatenadas por outros agentes que são complementares as representações iniciais dos sujeitos viajantes. Configurando dessa forma múltiplas apropriações de espaços.

Para problematizar uma possível visualização de tais questões, recorremos a Embratur enquanto um agente que sintetiza ações tanto em âmbito público como privado e que, com iniciativas que a princípio levariam a um desenvolvimento no viés de atrair pessoas e através dessas recursos econômicos, acaba levando a uma divulgação das potencialidades turísticas de maneira que gera especificidades espaciais, aqui pensadas pela questão das territorialidades. Assim, para além dos sentidos de atrair ou de ir, o discurso da Embratur, desde sua origem e, se quisermos para o futuro, pensando no Projeto Aquarela 2020 enquanto estratégia de marketing para atrair turistas para a Copa de 2014 e para os Jogos Olímpicos de 2016, dizem respeito as representações hegemonizadas de Brasil, consistindo na venda de desejos inexistentes nas espacialidades que recebem os que estão ao turismo (turi-estando) e que a efetivação apenas se realiza na viagem para o Brasil, para aqueles que segundo Haesbaert (2004) tem a possibilidade de escolher pela multiterritorialidade.

Salientamos a partir de Berger e Luckmann (2005) para uma pluralidade de sentidos e uma falha nas grandes estruturações, mesmo assim, ancorados em Harvey (1998), principalmente,

Geografia Ensino \& Pesquisa, v. 15, n.2, p. 105-116, maio./ago. 2011

Nabozny, A.; Fontana, C.

ISSN 2236- 4994 
destacamos que essas pluralizações não anulam o princípio da lucratividade enquanto elemento fundante das relações capitalistas. Cujo alguns agentes intencionalmente concatenam em suas ações múltiplos interesses, dos quais buscamos evidenciar no âmbito do Plano Aquarela como isso se evidencia numa busca por produzir uma imagem de Brasil, ao mesmo tempo fragilizando o espaço nacional. Em que a "cultura turística" parafraseando os termos de Guatarri (1986) efetivamente se configura num equivalente para produção de dessimetrias de força, ou seja, relações espaciais de poder.

Admitindo que hajam ruídos nas grandes estruturações reivindicamos, nos termos de Berger e Luckmann (2005), que a busca pelo desenvolvimento do turismo internacional possa levar em conta múltiplas comunidades de vida e, que essas efetivamente possam ganhar lugar e produzir outros sentidos para o turi-estar, vinculado as espacialidades de suas existências, efetivando por meio daqueles que podem multiterritorializar-se um ganho de espaço num duplo sentido (geográfico e metafórico), para aqueles precariamente territorializados.

\section{Referências}

ALFONSO, Louise Prado. EMBRATUR: Formadora de imagens da nação brasileira. Campinas: UNICAMP, 2006 (Dissertação de Mestrado). Programa de Pós -Graduação em Antropologia Social.

BERGER, Peter Ludwig; LUCKMANN, Thomas. Modernidade, Pluralidade e Crise de Sentido: A orientação do homem moderno. 2 ed . Petrópolis-RJ: Vozes, 2005.

BRASIL. Instituto Brasileiro de Turismo (site institucional). Disponível In: http://www.turismo.gov.br/turismo/o_ministerio/embratur/. Visitado: 20-07-2010.

BRASIL. Ministério do Turismo (site institucional). Disponivel In: http://www.turismo.gov.br/turismo/home.html. Visitado: 17-07-2010.

BRASIL. PLANO AQUARELA: Marketing Turístico Internacional do Brasil. Relatório Executivo. Brasília: 2003-2006

CARLOS, Ana Fani Alessandri. "Novas" contradições do espaço. In: DAMIANI, Amélia Luisa; CARLOS, Ana Fani Alessandri; SEABRA, Odette Carvalho de Lima. (Org.). 0 espaço no fim do século: a nova raridade. 2 ed. São Paulo: Contexto, 2001. p.62-74.

DI MÉO, Guy; BULÉON, Pascal. L'espace social. Lecture géographique des sociétés. Paris: Armand Colin, 2007.

GOMES, Paulo César da Costa. A Condição Urbana: Ensaios de Geopolítica da Cidade. Rio de Janeiro: Bertrand Brasil. 2006.

GUATTARI, Félix; ROLNIK, Suely. Micropolítica: Cartografias do Desejo. Petrópolis-RJ: Vozes, 1986.

HAESBAERT, Rogério. O Mito da Desterritorialização: do "Fim dos territórios" à multiterritorialidade. Rio de Janeiro: Bertrand Brasil, 2004.

Identidades territoriais: entre a multiterritorialidade e a reclusão territorial (Ou: Do

Geografia Ensino \& Pesquisa, v. 15, n.2, p. 105116, maio./ago. 2011

Estar Turista (turi-estar), Discursos Espaciais e Sentidos de Eficiência Multiterritorial: uma breve análise do Plano Aquarela (2003-2006) I Embratur hibridismo cultural à essencialização das identidades) In: ARAUJO, Frederico Guilherme Bandeira de; HAESBAERT, Rogério (org). Identidades e Territórios: Questões e olhares contemporâneos. Rio de Janeiro: ACCESS, 2007. p.33-56.

Dos múltiplos territórios à multiterritorialidade. In: HEIDRICH, Álvaro Luiz; COSTA, Benhur Pinós da; PIRES, Cláudia Luiza Zeferino; UEDA, Vanda (org). A emergência da multiterritorialidade. A resignificação da relação do humano com o espaço. Porto Alegre: Editora da UFRGS; Canoas: Editora da ULBRA, 2008. p.19-36. 
HALL, Stuart. A Identidade Cultural na Pós-Modernidade. 2. ed. Rio de Janeiro: DP\&A, 1998.

HARVEY, David. Condição pós-moderna. 7 ed. São Paulo: Loyola, 1998.

LEFEBVRE, Henri. A cidade do capital. 2 ed. Rio de Janeiro: DP\&A editora, 2001.

OLIVEIRA, Ariovaldo Umbelino de. Agricultura brasileira: Transformações recentes. In: ROSS. Jurandyr Luciano Sanches. (Org). Geografia do Brasil. São Paulo: Edusp, 2005. p.465-534.

SACK, Robert David. Human territoriality: its theory and history. Cambridge: University Press, 1986.

\section{Correspondência}

Almir Nabozny — Rua Frederico Bahls, 131. APTO 102. CEP 84010-560. Ponta Grossa. PR.

E- mail: almirnabozny@yahoo.com.br

Recebido em 24 de fevereiro de 2011.

Revisado pelo autor em 02 de julho de 2011.

Aprovado em 04 de julho de 2011. 